\title{
Dynamic Economic Dispatch and Control of a Stand-alone Microgrid in DongAo Island
}

\author{
Yiwei Ma ${ }^{\dagger}$, Ping Yang*, Hongxia Guo* and Yuewu Wang**
}

\begin{abstract}
A dynamic economic dispatch and control method is proposed to minimize the overall generating cost for a stand-alone microgrid in DongAo Island, which is integrated with wind turbine generator, solar PV, diesel generator, battery storage, the seawater desalination system and the conventional loads. A new dispatching strategy is presented based on the ranking of component generation costs and two different control modes, in which diesel generator and battery storage alternate to act as the master power source to follow system power fluctuation. The optimal models and GA-based optimization process are given to minimize the overall system generating cost subject to the corresponding constraints and the proposed dispatch strategy. The effectiveness of the proposed method is verified in the stand-alone microgrid in DongAo Island, and the results provide a feasible theoretical and technical basis for optimal energy management and operation control of stand-alone microgrid.
\end{abstract}

Keywords: Dynamic economic dispatch, Stand-alone microgrid, Diesel generator, Battery storage, Seawater desalination

\section{Introduction}

Stand-alone microgrid is commonly a small-scale autonomous electric power system, isolated from the main power grid $[1,2]$. In recent years, stand-alone microgrid has received much attention, as it is the most appropriate solution to power shortage demand in those remote island and mountain areas [3-5]. The basic requirement of a stand-alone microgrid system is to simultaneously achieve a secure, stable, economic, and reliable power supply to satisfy the load demand. Researches and practices show that a stand-alone microgrid integrated renewable energy sources (RES) with diesel generator and battery storage can offer the electric supply more reliably and economically [6], [7], and it has been developed and applied widely in remote island regions, China [8].

Economic dispatch modeling, strategy and simulation of stand-alone microgrid have received considerable attentions in the literature $[9,10]$. Considering the coupling constrains of battery storage [11] and the ramp rate constraints of generators [12], optimal dynamic economic dispatch is more effective and significant for stand-alone microgrid. The optimization objectives are presented to minimize the operation cost [13], emission cost [14] or total cost [15] while satisfying the operating limit constrains, power balance equation and reserve constrains, etc [16]. Thus, various algorithms such as Dynamic Programming (DP)

$\dagger$ Corresponding Author: School of Electric Power, South China University of Technology, China. (ma.yiwei@mail.scut.edu.cn)

* School of Electric Power, South China University of Technology, China.

** Guangdong Key Laboratory of Clean Energy Technology, China. Received: October 13, 2014; Accepted: March 2, 2015
[17], Simulated Annealing (SA) [18], Genetic Algorithm (GA) [19] and Evolutionary Programming (EP) [20] have been used to solve the economic dispatching and power energy management problem. However, the longer time of calculation is still their main shortcoming in determination of optimal solution for stand-alone microgrid with numerous distributed generation (DG) units. In addition, dispatch strategy is another main factor to determine the appropriate unit commitment and generation schedule of the available distributed generation units, combined with different control strategies [21, 22]. Moreover, it can improve calculation time effectively through less decision variables in most time intervals of the dispatch period.

Owning to the dynamic nature of stand-alone microgrid with diesel generator and battery storage, this paper presents an optimum dynamic economic dispatch method to minimize the overall generating cost of a stand-alone microgrid, considering two different master-slave control modes and GA-based optimization program. Section 2 gives the system configuration and two different masterslave control modes of the stand-alone microgrid. Section 3 presents an innovative dynamic dispatching strategy based on the ranking of unit generation cost and two different control modes. The optimal models and GAbased optimization process are proposed in Section 4. The performance of the proposed method is verified in the stand-alone microgrid in DongAo Island in Section 5. The conclusions are presented in Section 6.

\section{DongAo Microgrid Project}

DongAo Island is a southwest inhabited island in Zhuhai 


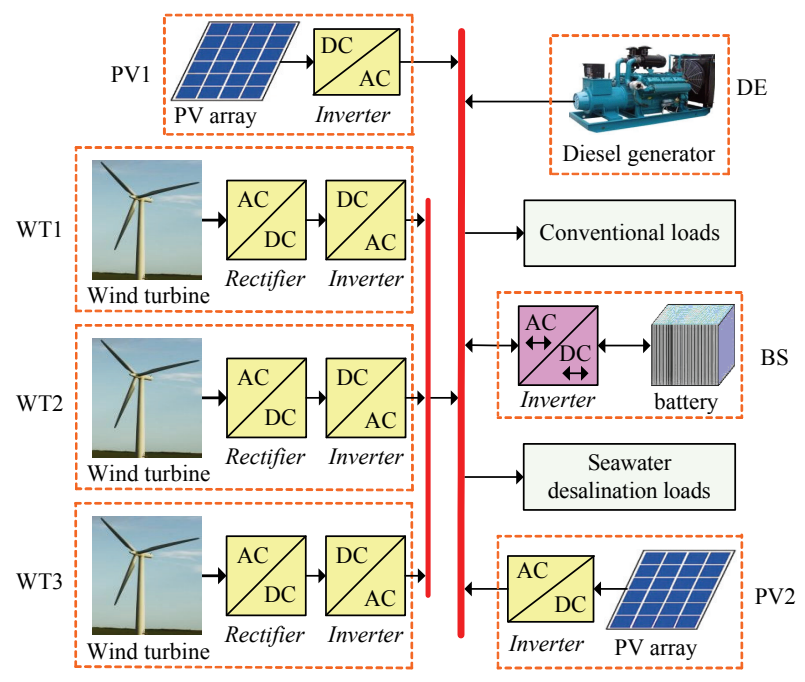

Fig. 1. Structure of DongAo microgrid

city, China, and the inhabitants of the island used to suffer the lower reliability and much higher prices of electricity and fuel while diesel generators are solely solution to supply limited power supply currently. Consequently, a stand-alone microgrid project has been developed with wind turbine generator (WT), solar PV generator (PV), diesel generator (DE), battery storage (BS), the seawater desalination system (L-des) and the conventional loads (Lcon) for an island village.

\subsection{System configuration}

Considering load distribution, renewable energy sources location and potentials, electric power quality and other concerns, an AC stand-alone microgrid is designed based on the hybrid resource energies, as shown in Fig. 1. It is noted that the battery energy storage system is not only to smooth the volatility of WT and PV, but also supply necessary power compensation to assist the existing DE to ensure the stability of system voltage and frequency. Moreover, the seawater desalination system serves as a controllable load to increase utilization of WT and PV. The optimum configuration of the DongAo microgrid was already chosen as $3 * 100 \mathrm{~kW}$ WT units, $2 * 50 \mathrm{~kW} \mathrm{PV}$ units, a $200 \mathrm{~kW}$ DE unit, a $100 \mathrm{~kW}^{*} 4 \mathrm{~h}$ BS unit, $2 * 30 \mathrm{~kW}$ the seawater desalination systems and $260 \mathrm{~kW} \max$ the conventional load.

\subsection{Master-slave control strategy}

The purpose of operation control strategy is to guarantee the operation stability and reliability of the stand-alone microgrid, and also consider economic cost requirement. Hence, according to the control characteristics and unit capacity of WT, PV, DE and BS, a master-slave control strategy is proposed with two different control modes for a stand-alone microgrid in DongAo Island. No matter which kind of control modes, WT and PV both operate in PQ control method to inject renewable energy power into microgrid, but the control methods of $\mathrm{BS}$ and $\mathrm{DE}$ are different as followings.

(1) Mode 1: BS acts as the master power source and employs V/f control method to track the system netload fluctuation and guarantee the frequency and voltage stability of the stand-alone microgrid. On the contrary, DE just becomes a backup power source to supply power to BS for particular conditions due to bad weather and others.

(2) Mode 2: DE acts as the master unit and use droop control method to maintain the operation stability of stand-alone microgrid. However, BS employs PQ control method to assist $\mathrm{DE}$ to improve renewable energy utilization and economic benefits.

\section{Economic Dispatch Strategy}

The dispatch strategy is intended to control the system by allocating various distributed generation units such that the load requirements are met with required power quality and also considering cost economy.

\subsection{Ranking of component generation cost}

Due to large difference of investment costs and operation costs among WT, PV, DE and BS units, it necessitated the unit generation cost of each type of generation units, and then determine a ranking of component generation cost for economic dispatch. The generation cost of generating unit normally involves the depreciation cost, maintenance and operation $(\mathrm{M} \& \mathrm{O})$ cost, fuel consumption cost, emission cost and price subsidies available for renewable energy sources [15], so it is formulated as follows.

$$
\begin{aligned}
C_{i}\left(P_{i}^{t}\right)= & C_{D C, i}\left(P_{i}^{t}\right)+C_{M O, i}\left(P_{i}^{t}\right)+C_{F C, i}\left(P_{i}^{t}\right) \\
& +C_{E C, i}\left(P_{i}^{t}\right)-E_{P S, i}\left(P_{i}^{t}\right)
\end{aligned}
$$

where $C_{i}\left(P_{i}^{t}\right)$ is the generation cost for unit $i$ to produce $P_{i}^{t} ; P_{i}^{t}$ is the generation power of unit $i$ at time $t ; C_{D C}, C_{M O}, C_{F C}, C_{E C}$ and $E_{P S}$ are the functions of the depreciation cost, $\mathrm{M} \& \mathrm{O}$ cost, fuel cost, emission cost and price subsidies, respectively.

Consequently, the generation cost curves of WT, PV, DE and BS units of DongAo microgrid are all piloted in Fig. 2, based on the optimum configuration results and historical data of wind and solar energy resources in 2013. It is obvious to know that the unit costs of WT, PV and BS all appear as the constant values per unit power because they are only the fixed costs of the depreciation cost and less $\mathrm{M} \& \mathrm{O}$ cost, as well as the price subsidies per unit power according to the renewable energy policy, no any variable cost of fuel and emission. However, the unit generating cost of DE is depicted as a curve because the fuel cost and 
emission cost are both formulated as the non-linear functions [21, 23].

As shown in Fig. 2, WT and PV are the first priority and second priority respectively in the dispatch schedule due to their lower generating cost levels $\left(U C_{W T}=2.059 ¥ / \mathrm{kWh}\right.$, $\left.U C_{P V}=3.587 ¥ / \mathrm{kWh}\right)$, compared to the higher costs of $\mathrm{DE}$ and BS $\left(U C_{B S}=4.490 ¥ / \mathrm{kWh}\right)$. In addition, there is an intersection point ( $P_{s p}=88 \mathrm{~kW}$ ) of the unit generating costs

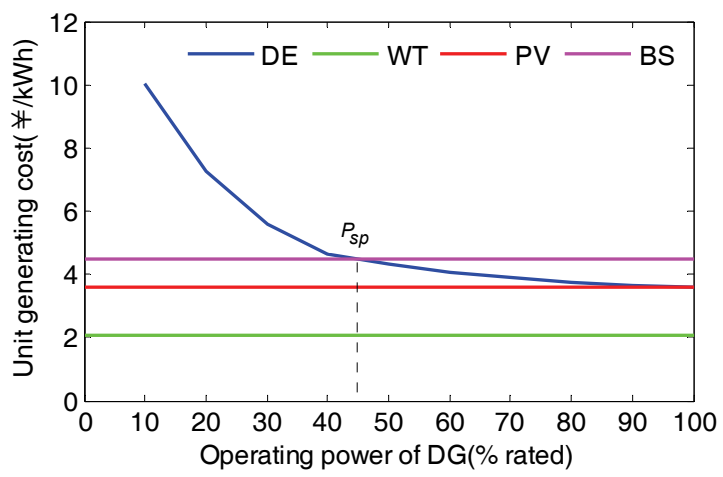

Fig. 2. Unit generation cost of distributed generation units between DE and BS, which means that DE is more economical than BS when its output power is bigger than the value of $P_{s p}$. Therefore, below this point, DE should be turned off and BS supplies the load.

\subsection{Economic Dispatch Strategy}

The dynamic dispatch strategy is an economic optimization control process for the energy flow management among different generating units of stand-alone microgrid. Combined with the control strategy and ranking of component generation costs discussed as above, the flowchart of the energy flow management in DongAo microgrid is presented in Fig. 3. In the proposed dynamic dispatch strategy, the operation power limit of master unit (MU) and SOC of BS are both the key parameters for the economic dispatch optimization of the stand-alone microgrid. Hence, these two parameters are both divided into four different subareas according to the physical characteristics and the necessary system spinning reserve requirement $\left(P_{M G-S R}^{t}\right)$, which is necessary to cover the system net load fluctuation $\left(P_{n e t-L}\right)$, as shown in Fig. 4.

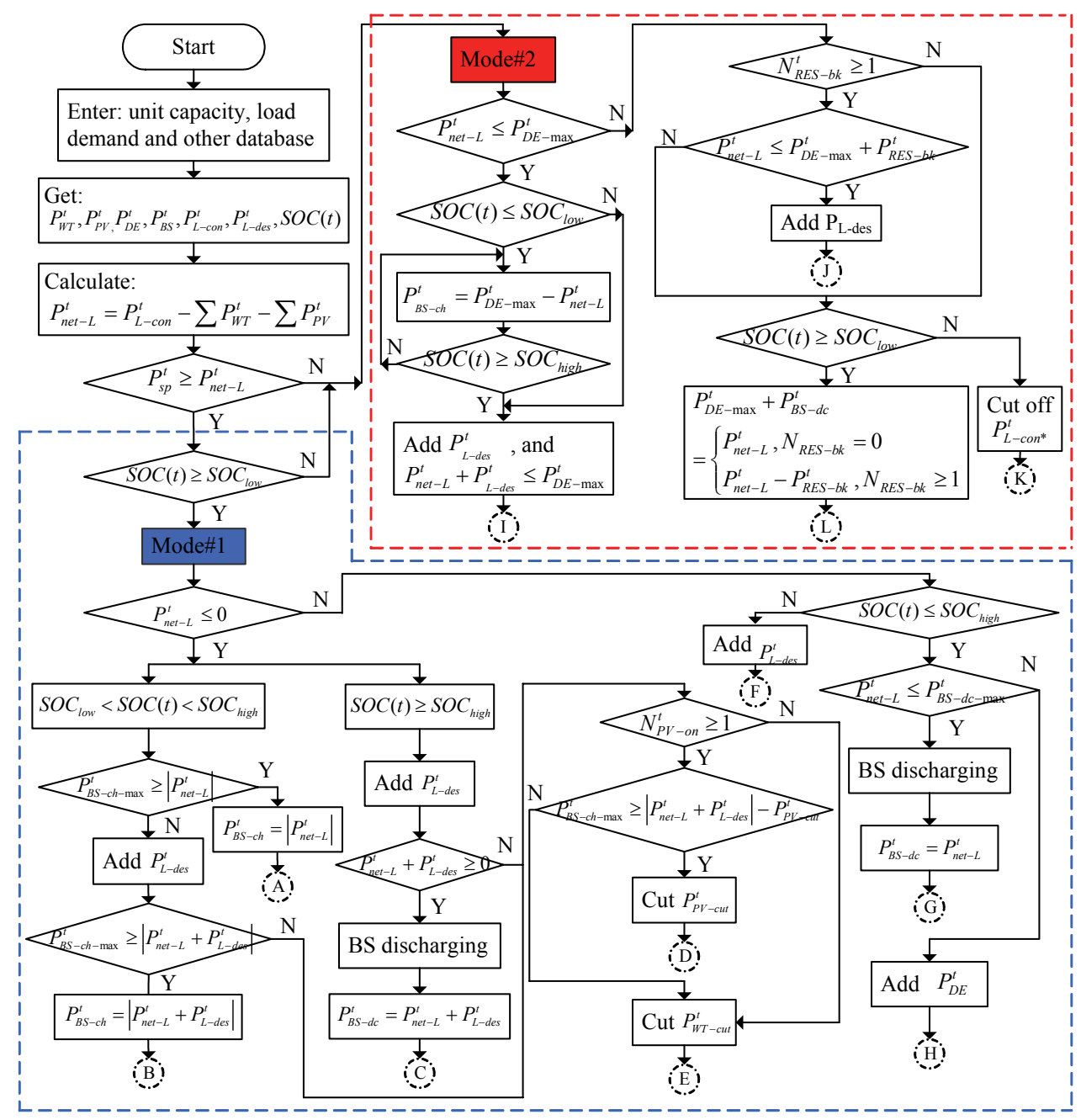

Fig. 3. Flowchart of economic dispatch in DongAo microgrid 


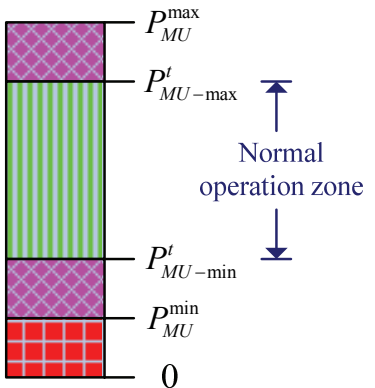

(a)

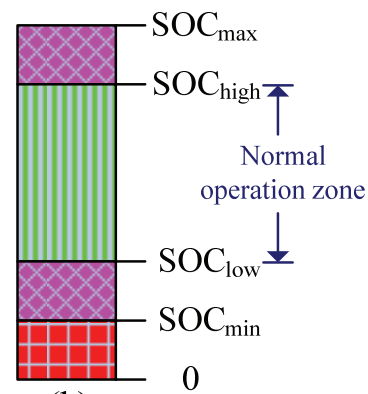

(b)

Fig. 4. Subarea graphs for (a) MU output power, (b) SOC

1) $P_{M U}^{\max }$ and $P_{M U}^{\min }$ are the technical maximum and minimum output power of the master unit like $\mathrm{DE}$ or BS, respectively. They both are normally set by factory. However, $P_{M U-\max }^{t}$ and $P_{M U-\min }^{t}$ are the generating power upper and lower limits of the master unit respectively, and they are formulated in Eq.(2), where $P_{M G-S R}^{t}$ is the system spinning reserve requirement of stand-alone microgrid.

$$
\left\{\begin{array}{l}
P_{M U-\max }^{t}=P_{M U}^{\max }-P_{M G-S R}^{t} \\
P_{M U-\min }^{t}=P_{M U}^{\min }+P_{M G-S R}^{t}
\end{array}\right.
$$

2) $S O C_{\max }$ and $S O C_{\min }$ are the technical maximum and minimum capacity of BS, respectively. $S O C_{h i g h}$ and $S O C_{\text {low }}$ are the upper and lower capacity limits of BS, in which BS is set to follow the system power fluctuation.

In the Fig. 3, from " $A$ " to " $L "$ indicate the specific dispatch set points among different distributed generation units and adjusting seawater desalination load under various operating conditions, and the followings are described in details. Please note that $P_{B S-c h}^{t}$ is the charging power of BS, $P_{B S-d c}^{t}$ is the discharging power of BS, $P_{n e t-L}^{t}$ is the system net load $\left(P_{n e t-L}^{t}=P_{L-c o n}^{t}-P_{W T}^{t}-P_{P V}^{t}\right), P_{L-d e s}^{t}$ is the seawater desalination load.

(1) A: BS is charging at power of $P_{B S-c h}^{t}=\left|P_{n e t-L}^{t}\right|$ until the battery SOC for charging reaches $S O C_{\text {high. }}$, so that BS can ensure sufficient reserve capacity to smooth the system power fluctuation.

(2) B: BS is charging at power of $P_{B S-c h}^{t}=\left|P_{n e t-L}^{t}+P_{L-d e s}^{t}\right|$ until the battery SOC for charging reaches $S O C_{\text {high. }}$, after the seawater desalination system $\left(P_{L-d e s}^{t}\right)$ is turned on to assist BS to absorb the surplus power supply of RES.

(3) $\mathrm{C}$ : BS is discharging to satisfy the system net load and the seawater desalination system $\left(P_{L-d e s}^{t}\right)$.

(4) D: Cut out a certain number of PV units (PV-cut) to reduce the PV power output $\left(P_{P V-c u t}^{t}\right)$ and $\mathrm{BS}$ is charging until $S O C_{\text {high }}$ is reached just for necessary reserve capacity, when the seawater desalination system $\left(P_{L-d e s}^{t}\right)$ cannot assist BS to maintain the system power balance.

(5) E: Cut out a certain number of WT units (WT-cut) to reduce the wind power output $\left(P_{W T-c u t}^{t}\right)$ and assist BS to maintain the system power balance and be charging until $S O C_{\text {high }}$ is reached.

(6) F: the seawater desalination system $\left(P_{L-d e s}^{t}\right)$ is turned on to assist BS to discharge the excessive power.

(7) G: BS is discharging at power of $P_{B S-d c}^{t}=\left|P_{n e t-L}^{t}\right|$ until the battery SOC for discharging reaches $S O C_{\text {low. }}$.

(8) $\mathrm{H}$ : A certain number of the conventional electric load $\left(P_{L-c o n-c u t}^{t}\right)$ is cut out for system power balance, when there is no sufficient power supply from RES and BS in mode 1.

(9) I: The seawater desalination load $\left(P_{L-d e s}^{t}\right)$ is turned on to regulate DE running at higher operation power level, after BS is charged to reach $S O C_{\text {high }}$ status.

(10) J: The seawater desalination system $\left(P_{L-d e s}^{t}\right)$ is turned on to absorb the excessive power supply and maintain the system power balance.

(11) K: A certain number of the conventional electric load $\left(P_{L-c n^{*}}^{t}\right)$ is cut out to keep system power balance, while $\mathrm{DE}$ is running its maximum operation power $\left(P_{D E-\max }^{t}\right)$ and BS reaches its lower SOC ( $\left.S O C_{\text {low }}\right)$.

(12) L: BS is discharging to assist DE to satisfy the system load demand until the lower battery SOC $\left(S O C_{l o w}\right)$ for discharge is reached.

As mentioned above, the proposed economic dispatch strategy is integrated with two different control modes, which is aimed to maximize RES utilization such as WT and PV units and reduce the fuel consumption cost and pollution emission cost resulted from DE unit. In addition, the seawater desalination system, as a controllable load, also plays a necessary role to increases RES utilization.

\section{GA-based Economic Optimization}

\subsection{System economic optimization}

The objective of dynamic economic dispatch is to allocate the load demands among the committed units so as to minimize the system total generating cost over a dispatch period, while satisfying a set of constraints [13]. Hence, the system economic optimization is formulated in Eq. (3), where $\mathrm{N}$ is the number of the generation units available.

$$
\min C_{M G}^{T}(P)=\int_{0}^{T} \sum_{i=1}^{N} C_{i}\left(P_{i}^{t}\right)
$$

Subject to a set of constraints [24]-[26], consisting of (i) system power balance, (ii) generating power limits of the master unit, (iii) generating power limits of other generating unit, (iv) system reserve capacity requirements, (v) ramp rate limits, (vi) shortest start-stop time constraints and (vii) capacity limit of BS. 


$$
\left\{\begin{array}{l}
\sum_{i=1}^{N} P_{i}^{t}-P_{M G-\text { surplus }}^{t}=P_{L-c o n}^{t}+P_{L-\text { des }}^{t} \\
P_{M U, m i}^{t} \leq P_{M U i}^{t} \leq P_{M U, \max }^{t} \\
P_{i}^{\min } \leq P_{i}^{t} \leq P_{i}^{\max } \\
\sum_{i=1}^{N} P_{i, S R}^{t} \geq P_{M G-S R}^{t} \\
-D R_{i} \cdot \Delta t \leq P_{i}^{t+1}-P_{i}^{t} \leq U R_{i} \cdot \Delta t \\
T_{i} \geq T_{i}^{\min } \\
S O C_{\min } \leq S O C(t) \leq S O C_{\max }
\end{array}\right.
$$

where $P_{M G-s u r p l u s}$ is the system surplus power; $P_{L-c o n}$ is the conventional electric load demand; $P_{L-d e s}$ is the seawater desalination load; $P_{M U, \min }^{t}$ and $P_{M U, \max }^{t}$ are the minimum and maximum output power limits of the master unit; $P_{i}^{\min }$ and $P_{i}^{\max }$ are the technical minimum and maximum output power limits of other generating unit $i$, respectively; $P_{i, S R}^{t}$ is the spinning reserve contribution of unit $i ; P_{M G, S R}^{t}$ is the system spinning reserve requirement; $D R_{i}$ and $U R_{i}$ are the maximum ramp up/down rates of unit $i ; T_{i}$ and $T_{i}^{\min }$ are the real operating time and required minimum operation time of unit $i$.

\subsection{GA-based optimization program}

The optimal dynamic economic dispatch is a constrained optimization problem with an objective cost function to be minimized, subject to a set of operation constraints and the control set points of the proposed dispatch strategy shown in Fig. 3. Hence, the economic optimization program can be broadly presented in Fig. 5, which consists of four key sections: input database, supporting database, simulation algorithm and output solution. The simulation algorithm employees a genetic algorithm to solve the economic optimization problem, and the supporting database consists of different constraints and control set points. The basic database mainly consists of scheduling of different distributed generating units, unit generating cost of different units, load demand profile, unit capacity and numbers of generating units of the stand-alone microgrid.

GA is a global optimum search technique based on the concepts of natural selection and survival of the fittest, and has been applied to various optimization problems [6, 27]. For the economic dispatch optimization of stand-alone

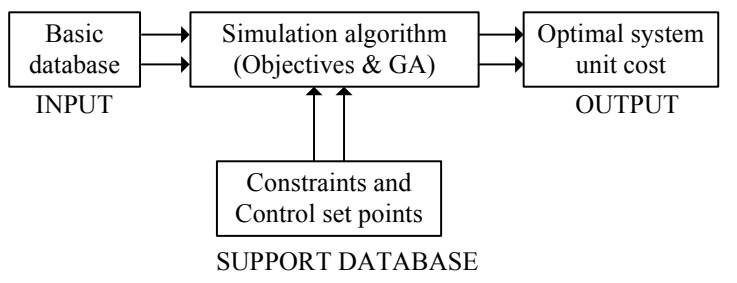

Fig. 5. Economic optimization program of microgrid

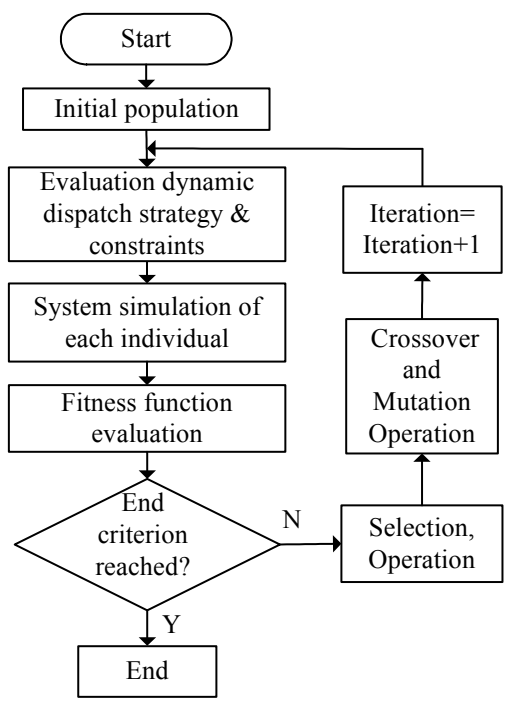

Fig. 6. Flowchart of GA-based optimization process

microgrid, a GA is used to determine the unit commitment and the generation levels of WT, PV, DE and BS in such a stable, economic and reliable way for the stand-alone microgrid in DongAo Island. Thus, the GA-based optimization program is presented in Fig. 6 with the fitness function, expressing the goal of the optimization. The performance of each algorithmic population generated as part of the GA operation is evaluated by the fitness function (Eq. 3) under the corresponding technical limits or constraints (Eq. 4) and the proposed dynamic dispatch strategy (Fig. 3). Each new population is produced by the selection, mutation and crossover procedures, well defined in the literature. The optimization is considered completely when the end-point criterion is satisfied.

\section{Result and Discussion}

The stand-alone microgrid in DongAo Island indicated in Fig. 1 is used to demonstrate the performance of the proposed method. The parameters of $P_{M U}^{\max }, P_{M U \text { max }}^{t}, P_{M U-\min }^{t}$, $P_{M U}^{\min }, S O C_{\max }, S O C_{\text {high }}, S O C_{\text {low }}, S O C_{\text {min }}$ are set as $1,0.8 \mathrm{pu}$, $0.44 \mathrm{pu}, 0.2 \mathrm{pu}, 1,0.85 \mathrm{pu}, 0.3 \mathrm{pu}, 0.2 \mathrm{pu}$, respectively. For GA algorithm, the population size is 50, evolutionary generations are 400 , crossover rate is 0.3 , and mutation rate is 0.4 . The time interval is 5 minutes, and the length of time period is one day ( 24 hours), which means a cycle contains 288 periods. Moreover, many tests are conducted to show the performance of the model and method under various conditions.

The renewable energy sources like WT and PV units work at MPPT mode to maximize their utilization. The output power profiles of WT, PV and the conventional load demand are all shown in Fig. 7, based on historical data collected at DongAo Island in a typical day of 2013 year. It is observed that there are great differences between the load demand fluctuation and output power fluctuation of 


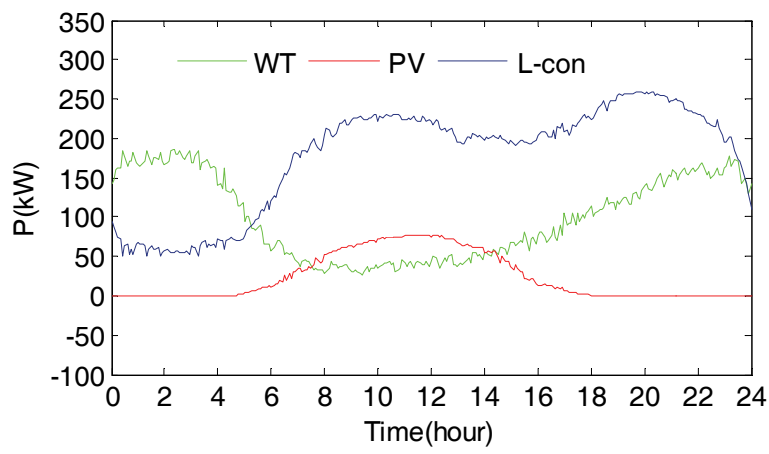

Fig. 7. The power profile of WT, PV and L-con

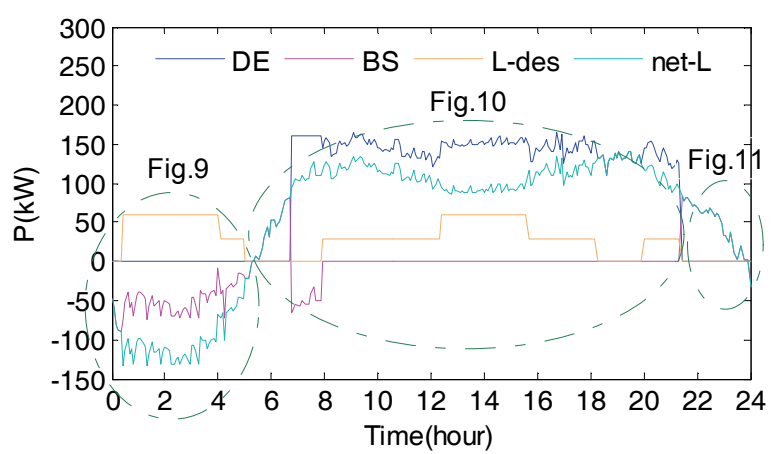

Fig. 8. The performance under the proposed method

\section{WT and PV units.}

According to the proposed simulation program as above, the optimal economic operation performance of DongAo microgrid is depicted in Fig. 8, which considered three typical conditions: (a) the output power of RES unit is more than the load of the conventional electric load in a period of time, shown in Fig. 9; (b) the demand of the conventional load is far greater than the sum of output power generated by RES unit, owning to the relative bad conditions of RES but the higher load demand in a period of time, as shown in Fig. 10; (c) The net-load power fluctuations is within a narrow range in a period of time, shown in Fig. 11.

As shown in Fig. 9, during 0:00am to 5:10am, the netload power is negative because of the good conditions of RES (special wind resource) but the lower demand of the conventional load. At that time, DongAo microgrid was operating in the control mode 1, in which BS was the master unit to absorb the surplus power generated by RES units as to maintain the system power balance. Moreover, the seawater desalination systems were also turned on to improve the RES utilization during 0:25am to 4:55am because of $\left|P_{n e t-L}\right|>P_{B S-c h \text {-max }}$, and then cut out within two periods of from 0:00am to 0:25am and during 4:55am to 5:10 am due to $\left|P_{n e t-L}\right|<P_{B S-c h-\max }$.

As shown in Fig. 10, during 6:45 am to $21: 20 \mathrm{pm}, \mathrm{DE}$ unit was operating to follow the system power fluctuation, and the system net load was bigger than the value of $P_{s p}(88 \mathrm{~kW})$, as indicated in Fig. 2. From 6:45 am to 7:50 am, DE was operated at the maximum economic power to

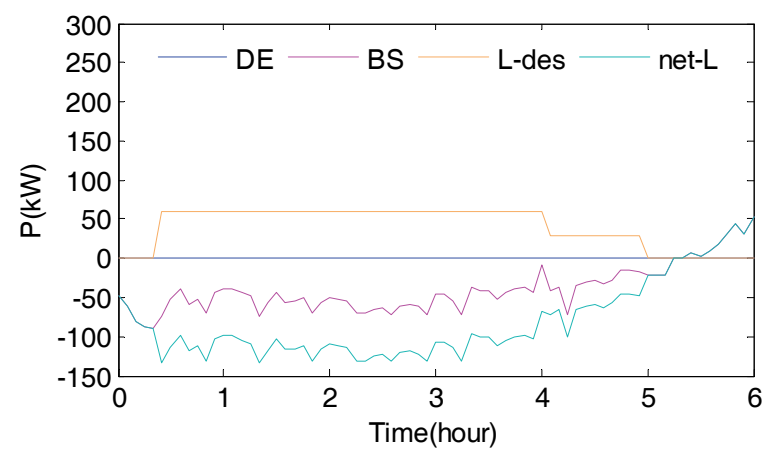

Fig. 9. Economic optimization profile under condition (a)

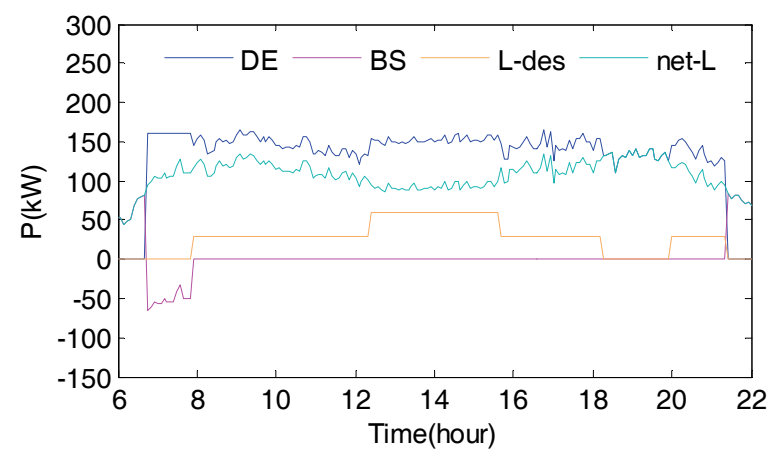

Fig. 10. Economic optimization profile under condition (b)

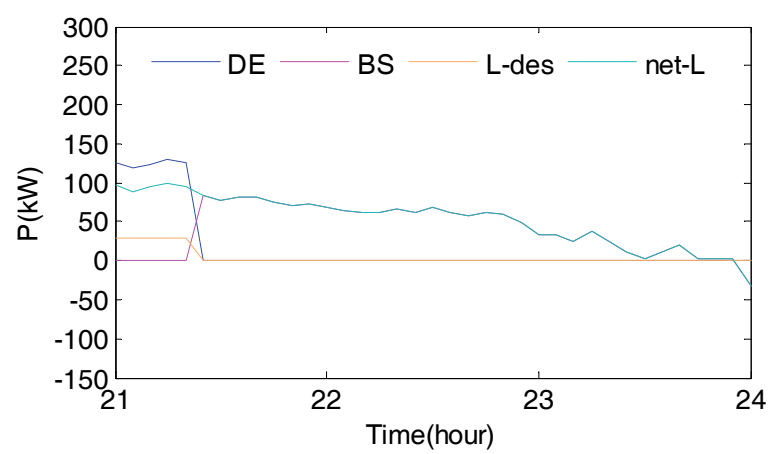

Fig. 11. Economic optimization profile under condition (c)

meet the net load demand as well as charge BS until battery $S O C_{\text {high }}$ was reached. Since 7:50am, the seawater desalination systems were turned on instead of BS unit with $S O C_{\text {high }}$, so that DE continued operating at the higher output power level just for reducing the fuel consumption cost and pollution emission cost.

In the Fig. 11, during 21:20pm to $24: 00 \mathrm{pm}$, the system net load is positive but lower than the value of $P_{s p}(88 \mathrm{~kW})$. Thus, as the master unit, BS unit was discharging in such a manner as to smooth the system net load fluctuation. In addition, one more similar condition occurred during 05:10am to 06:45am as shown in Fig. 8.

Fig. 12 describes the SOC curve of BS unit during a 24hour dispatch period, which shows three different states: charging, discharging and standby. Combined with Fig.7, it is easy to know: (1) BS had two charging stages in different control modes: mode 1 (BS as the master unit) 


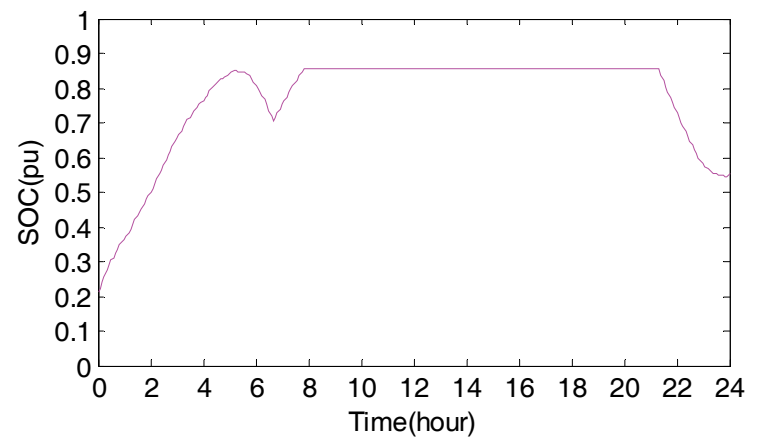

Fig. 12. SOC curve of BS

during 0:00am to 5:10 am and mode 2 (DE as the master unit) during 6:45am to 7:50 am. (2) Two discharging stages both in control mode 1 (BS as the master unit) occurred during $05: 15 \mathrm{am}$ to $06: 40 \mathrm{am}$ and $21: 20 \mathrm{pm}$ to $24: 00 \mathrm{pm}$. (3) The standby stage occurred during $8: 15 \mathrm{am}$ to $21: 20 \mathrm{pm}$ as DE was the master unit with sufficient reserve capacity, and battery $S O C_{\text {high }}$ was reached. It follows that BS unit can smooth RES power fluctuation to improve the RES utilization under the control mode 1 , but also can assist DE to operate at higher output power for reducing the fuel consumption cost and emission cost under the control mode 2 .

In order to analyze the influence of the proposed method on the microgrid economic dispatch problem, this paper gives the result comparisons between two different methods: (i) the proposed method that adopts GA and two modes of mode1 and mode 2, and (ii) the traditional method that just have mode 2 and no GA optimization, indicated in section 2. The economic operation performance of adopting the traditional method is shown in Fig. 13. The comparisons of results are shown in Table 1, which clearly indicates the proposed method is effective than the traditional method. Combined with Fig. 8 and Fig. 13, it is easy to know the root cause is the much longer run-time of

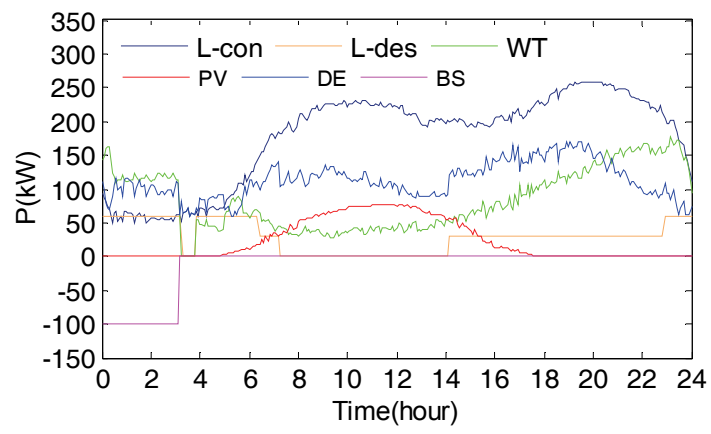

Fig. 13. The performance under the traditional method

Table 1. Comparisons between two different methods

\begin{tabular}{c|c|c}
\hline & $\begin{array}{c}\text { The proposed } \\
\text { method }\end{array}$ & $\begin{array}{c}\text { The traditional } \\
\text { method }\end{array}$ \\
\hline Calculation time (second) & 18.52 & 47.23 \\
\hline Optimization results $(Y)$ & 200413.5850 & 223848.5513 \\
\hline
\end{tabular}

DE and less utilization of RES even though RES is sufficient to meet load demand.

Based on the above, it can be seen that the proposed method can maximize the RES utilization and cause DE to reduce run-time and run at higher power level correspondingly, which further minimize of DE fuel cost and emission cost so as to minimize the system generating cost of microgrid. The root cause is to set BS as the master unit to further reduce system generating cost, which can not only just utilize RES power to meet load but also run the system peak shaving function as to minimize DE fuel and emission.

\section{Conclusion}

The joint-optimization of dynamic economic dispatch and control method has been proposed for the stand-alone microgrid project in DongAo Island, China, which is integrated with WT, PV, DE, BS, the seawater desalination system and the conventional electric load. The optimal models were established based on careful study of the various optimization objectives combinations of depreciation cost, maintenance and operation cost, fuel consumption cost, airborne pollutant emission cost and price subsidies available just for renewable energy sources. The proposed dispatch strategy was integrated with two different control modes, where DE and BS units alternate to operate as the master unit to maintain the system operation stability as well as maximize the RES generation utilizations and minimize the fuel and emission cost resulted from DE. The proposed method was verified by the economic dispatch optimization simulation studies in DongAo microgrid project, and the results provide a feasible theoretical and technical basis for optimal energy management and operation control of stand-alone microgrid.

\section{Acknowledgements}

This work was supported jointly by the National High Technology Research and Development Program (863 Program-2014AA052001), the Science and Technology Planning Project of Guangdong Province(2012B04030300 5), Guangzhou Nansha District Science and Technology Plan Project (2013P005), the China Southern Power Grid Limited Science and Technology Project (K-KY2014-009).

\section{References}

[1] G. Kyriakarakos, A.I. Dounis, S. Rozakis, et. al., "Polygeneration microgrids: a viable solution in remote areas for supplying power, potable water and hydrogen as transportation fuel," Apply Energy, Vol. 88, No. 12, pp. 4517-4526, Dec. 2011. 
[2] S. Rehman, L.M. Al-Hadhrami, "Study of a solar PVdiesel-battery hybrid power system for a remotely located population near Rafha, Saudi Arabia," Energy, Vol. 35, No. 12, pp. 4986-4995, Dec. 2010.

[3] S.Obara, M. Kawai, O. Kawae, et. al., "Operational planning of an inde pendent microgrid containing tidal power generators, SOFCs, and photovoltaics," Apply Energy, Vol. 102, pp. 1343-1357, Feb. 2013.

[4] M. Ross, R. Hidalgo, C. Abbey, et. al., "Energy storage system scheduling for an isolated microgrid," IET Renewable Power Generation, Vol. 5, No. 2, pp. 117-123, Mar. 2011.

[5] Jong-Yul Kim, Seul-Ki Kim, June-Ho Park, "Contribution of an Energy Storage System for Stabilizing a Microgrid during Islanded Operation," Journal of Electrical Engineering \& Technology, Vol. 4, No. 2, pp. 194-200, May 2009.

[6] Hongxing Yang, Wei Zhou, Lin Lu, et. al., "Optimal sizing method for stand-along hybrid solar-wind system with LPSP technology by using genetic algorithm," Solar Energy, Vol. 82, No. 4, pp. 354-367, Apr. 2008.

[7] E.I. Vrettos, S.A. Papathanassiou, "Operating policy and optimal sizing of a high penetration RES-BESS system for small isolated grids," IEEE Transactions on Energy Conversion, Vol. 26, No. 3, pp. 744-756, Sep. 2011.

[8] Bo Zhao, Xuesong Zhang, Peng Li, et. al., "Optimal sizing, operating strategy and operational experience of a stand-alone microgrid on Dongfushan Island," Applied Energy, Vol. 113, pp. 1656-1666, Jan. 2014.

[9] Yen-Haw Chen, Su-Ying Lu, Yung-Ruei Chang, et, al., "Economic analysis and optimal energy management models for microgrid systems: a case study in Taiwan," Apply Energy, Vol. 103, pp. 145-154, Mar. 2013.

[10] H. Morais, P. Péter, P. Pedro, et. al., "Optimal scheduling of a renewable microgrid in an isolated load area using mixed-integer linear programming," Renewable Energy, Vol. 35, No. 1, pp. 151-156, Jan. 2010.

[11] Xiaoping Liu, Ming Ding, Jianghong Han, et al, "Dynamic economic dispatch for microgrids including battery energy storage," in Proceeding of 2nd IEEE International Symposium on PEDG, pp. 914917, Hefei, Jun. 2010.

[12] K.S. Shailti, A. Natarajan, "Constrained optimization using evolutionary programming for dynamic economic dispatch," in Proceedings of ICISIP, pp. 314-319, Bangalore, Jan. 2005.

[13] X.S. Han, H.B. Gooi, "Effective economic dispatch model and algorithm," International Journal of Electrical Power \& Energy Systems, Vol. 29, No. 2, pp. 113-120, Feb. 2007.

[14] M. Basu, "Dynamic economic emission dispatch using evolutionary programming and fuzzy satisfying method," International Journal of Emerging Electric Power Systems, Vol. 8, No. 4, pp. 1-15, Oct. 2007.

[15] Ming Ding, Yingyuan Zhang, Meiqin Mao, et. al., "Economic operation optimization for microgrids including $\mathrm{Na} / \mathrm{S}$ battery storage," Proceedings of the CSEE, Vol. 31, No. 4, pp. 7-14, Feb. 2011.

[16] X.S. Han, H.B. Gooi, D.S. Kirschen, "Dynamic economic dispatch: feasible and optimal solutions," IEEE Transaction on Power System, Vol. 16, No. 1, pp. 22-28, 2001.

[17] W.R. Barcedo, P. Rastgonfard, "Dynamic economic dispatch using the extended security constrained economic dispatch algorithm," IEEE Transactions on Power Systems, Vol. 12, No. 2, pp. 961-967, 1997.

[18] K.P. Wong, C.C. Fung, "Simulated annealing based economic dispatch algorithm", IEE Proceeding- $C$, Vol. 140, No. 6, pp. 509-515, Nov. 1993.

[19] M. Basu, "Dynamic economic emission dispatch using nondominated sorting genetic algorithm-II," International Journal of Electrical Power and Energy Systems, Vol. 30, pp. 140-149, Feb. 2008.

[20] J. Yuryevich, K.P. Wong, "Evolutionary programming based optimal power flow algorithm", IEEE Transactions on Power Systems, Vol. 14, No. 4, pp. 1245-1250, 1999.

[21] C. Dennis Barley, C. Byron Winn, "Optimal dispatch strategy in remote hybrid power systems," Solar Energy, Vol. 58, No. 4-6, pp. 165-179, Oct.-Dec. 1996.

[22] Ajai Gupta, R.P. Saini, M.P. Sharma, "Modelling of hybrid energy system-Part II: Combined dispatch strategies and solution algorithm," Renewable Energy, Vol. 36, No. 2, pp. 466-473, Feb. 2011.

[23] O. Skarstein, K. Uhlen, "Design considerations with respect to long-term diesel saving in wind/diesel plants," Wind Engineering, Vol.72-78, No.13, 1989.

[24] Hongbin Wu, Xingyue Liu, Ming Ding, "Dynamic economic dispatch of a microgrid: mathematical models and solution algorithm," International Journal of Electrical Power and Energy Systems, Vol.63, pp. 336-346, Dec.2014.

[25] Kaile Zhou, Shanlin Yang, Zhiqiang Chen, et. al., "Optimal load distribution model of microgrid in the smart grid environment," Renewable and Sustainable Energy Reviews, Vol.35, pp.304-310, Jul. 2014.

[26] Minh Y Nguyen, Nack-Hyun Choi, Yong-Tae Yoon, "DP formulation of microgrid operation with heat and electricity constraints," Journal of Power Electronics, Vol. 9, No. 6, pp. 919-928, Nov. 2009.

[27] Qingfeng Tang, Nian Liu, Jianhua Zhang, “Optimal operation method for microgrid with wind / PV / diesel generator / battery and desalination," Journal of Applied Mathematics, pp.1-12, Jun. 2014. 


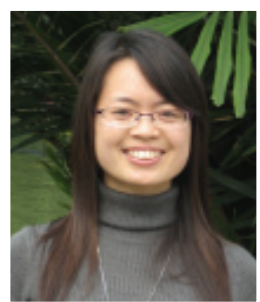

Yiwei Ma received her Master degree in Electrical Engineering from South China University of Technology (SCUT), China, in 2007. Currently, she is pursuing the Ph.D degree at school of electric power of SCUT. Her research interests include distributed generation, microgrid and smart grid.

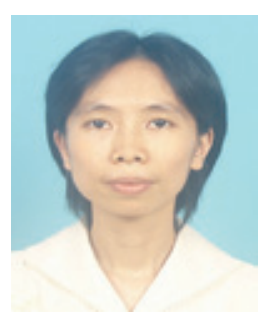

Ping Yang received her Ph.D degree in Electrical Engineering from South China University of Technology (SCUT), China, in 1998. She is presently a Professor in the same University. Her research interests include power electronic modeling and control, distributed generation and microgrid.

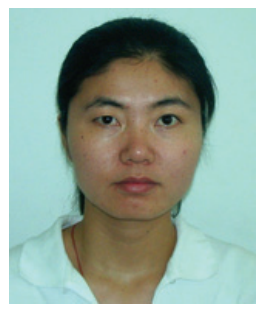

Hongxia Guo received her Ph.D degree in Electrical Engineering from South China University of Technology (SCUT), China, in 2005. She is presently an Associate Professor in the same university. Her research interests include: microgrid energy management, power electronic modeling and control and multi-agent system.

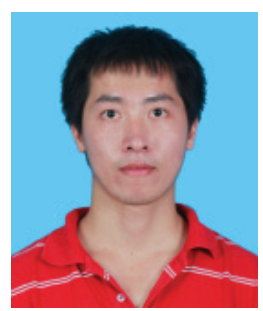

Yuewu Wang received his Master degree in Electrical Engineering from Guangxi University, China, in 2010. He is currently pursuing the $\mathrm{Ph} . \mathrm{D}$ degree at South China University of Technology (SCUT). His research interests include digital control technique and renewable energy generation system. 